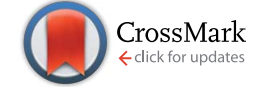

Cite this: RSC Adv., 2015, 5, 10254

Received 30th October 2014 Accepted 7th January 2015

DOI: $10.1039 / c 4 r a 13511 c$

www.rsc.org/advances

\section{A new soft dielectric silicone elastomer matrix with high mechanical integrity and low losses $\uparrow$}

\author{
F. B. Madsen, L. Yu, A. E. Daugaard, S. Hvilsted and A. L. Skov* \\ Though dielectric elastomers (DEs) have many favourable properties, the issue of high driving voltages limits \\ the commercial viability of the technology. Driving voltage can be lowered by decreasing the Young's \\ modulus and increasing the dielectric permittivity of silicone elastomers. A decrease in Young's modulus, \\ however, is often accompanied by the loss of mechanical stability and thereby the lifetime of the DE. A \\ new soft elastomer matrix, with no loss of mechanical stability and high dielectric permittivity, was \\ prepared through the use of alkyl chloride-functional siloxane copolymers. Furthermore, the increase in \\ dielectric permittivity (43\%) was obtained without compromising other important properties of DEs such \\ as viscous and dielectric losses as well as electrical breakdown strength.
}

\section{Introduction}

Dielectric elastomers (DEs) represent a new and promising electromechanical transducer technology which is based on an elastomer film sandwiched between two thin and compliant electrodes. Polydimethylsiloxane (PDMS) elastomers are one of the most frequently used materials for DEs, due to their high efficiency, fast response and low viscous losses, signifying that they can be operated at higher frequencies but with lower losses compared to, for example, acrylics or polyurethanes. ${ }^{\mathbf{1 , 2}}$ Furthermore, DEs have the ability to undergo large deformations when stimulated by electrical fields or to generate electrical energy when subjected to mechanical strain, and they also have the potential to be employed in a diverse range of advanced electromechanical applications such as flat screen loud speakers, ${ }^{3}$ Braille displays, ${ }^{4}$ active vibration control ${ }^{5}$ and wave energy harvesting, ${ }^{6}$ due to its simple and flexible working principle.

Currently, a few issues, such as high driving voltages (several $\mathrm{kV}$ 's), limit the commercial viability of DE technology. Driving voltage can be lowered by decreasing the thickness or the Young's modulus of the elastomer or by increasing the dielectric permittivity of the elastomer material. A reduction in elastomer film thickness, though, will have the greatest impact on reducing driving voltage and has the advantage of upholding dielectric loss and breakdown strength. A thickness of 10-20 $\mu \mathrm{m}$ has been reached in current large-scale processing, and further reductions could result in the increased importance of

Danish Polymer Centre, Department of Chemical and Biochemical Engineering, Technical University of Denmark, DTU, Søltofts Plads, Bldg. 227, $2800 \mathrm{Kgs}$. Lyngby, Denmark.E-mail: al@kt.dtu.dk

$\dagger$ Electronic supplementary information (ESI) available: Materials, synthesis procedures, elastomer compositions and TGA thermograms. See DOI: $10.1039 / \mathrm{c} 4 \mathrm{ra13511c}$ inhomogeneities, which in turn will produce localised areas of high electrical fields and stresses and ultimately result in premature electrical breakdown. ${ }^{2}$ Many studies during recent years have focused on increasing the dielectric permittivity of silicone elastomer materials for DEs, in order to increase the energy density of the material and thereby decrease the necessary driving voltage. ${ }^{7,8}$ This has often been achieved through the use of high-permittivity metal oxide fillers such as $\mathrm{TiO}_{2}{ }^{9-14}$ $\mathrm{BaTiO}_{3}{ }^{14-16}$ and $\mathrm{Al}_{2} \mathrm{O}_{3} \cdot{ }^{14}$ The disadvantage of using such composite-type systems, however, amongst other things, is that the Young's modulus tends to increase significantly, thereby decreasing achievable strain and increasing the necessary driving voltage. Other studies have attempted to decrease the Young's modulus using solvent techniques ${ }^{17}$ or bimodal networks. ${ }^{\mathbf{1 8 , 1 9}}$ Furthermore, several studies have tried to create improved materials through a combination of increased dielectric permittivity and a decreased Young's modulus, in order to achieve a synergistic impact on lowering the voltage. This includes the use of blends such as PDMS/poly(hexylthiophene) ${ }^{20}$ and PDMS/polyethylene glycol ${ }^{21}$ and a blend of a cyanopropylfunctional PDMS and a PDMS matrix, where the cyanofunctional PDMS acts both as a high permittivity filler and as a plasticiser. ${ }^{22}$ These systems showed improved electromechanical strain response, since both increased dielectric permittivities and decreased Young's moduli were obtained. Decreasing the Young's modulus, though, can introduce significant changes in several important properties, such as viscous loss, hysteresis and tear strength. In other words, the mechanical stability and integrity of the elastomer are often lost, thus compromising the long-term stability and lifetime of the material. In addition, the above mentioned systems all showed reduced dielectric breakdown strengths due to increased dielectric losses.

The aim of this work is to create a new type of soft silicone elastomer matrix with increased dielectric permittivity and 
electromechanical strain response, but without compromising important properties such as dielectric loss, dielectric breakdown strength and viscous loss and thereby maintaining the mechanical integrity of the elastomer. Instead of using additives to silicone elastomer systems, this work is based on a new type of functional silicone copolymer containing alkyl chloride siloxane units. The compositions of the new copolymers are tuneable, as the concentration of alkyl chloride segments as well as the molecular weight of the copolymers can be varied accurately, depending on the final desired properties of the elastomers. The increase in dielectric permittivity stems from the high dipole moment of the chloride groups. Furthermore, the bulky nature of the alkyl chloride units yields a larger free volume around these groups than around the methyl groups on non-functional PDMS. This results in a less dense material with a lower Young's modulus. We will demonstrate how the final properties of DEs based on alkyl chloride functional copolymers are influenced and improved by this structural change in the silicone elastomer and that important properties such as dielectric and viscous losses, as well as dielectric breakdown strength, are not compromised compared to a PDMS elastomer.

\section{Experimental}

\section{Materials and methods}

Vinyl-terminated PDMS, DMS-V31 $\left(\bar{M}_{\mathrm{w}} \approx 28000 \mathrm{~g} \mathrm{~mol}^{-1}\right)$, and a hydride-functional cross-linker, HMS-301, were acquired from Gelest Inc. The platinum cyclovinylmethyl siloxane complex catalyst (511) was purchased from Hanse Chemie, while silicon dioxide amorphous hexamethyldisilazane-treated particles (SIS6962.0) were purchased from Fluorochem. The inhibitor Pt88 was acquired from Wacker Chemie AG, and all other chemicals were acquired from Sigma-Aldrich and used as received, unless otherwise stated.

Fourier transform infrared (FTIR) spectroscopy was conducted on a Perkin-Elmer Spectrum One model 2000 Fourier Transform Infrared apparatus equipped with a universal attenuated total reflection accessory on a $\mathrm{ZnSe} /$ diamond composite. Spectra were recorded in the range of 4000-650 $\mathrm{cm}^{-1}$ with $4 \mathrm{~cm}^{-1}$ resolution and 16 scans. Nuclear magnetic resonance (NMR) spectroscopy ( ${ }^{1} \mathrm{H}$ and ${ }^{13} \mathrm{C}-\mathrm{NMR}$ ) experiments were performed on a Bruker $300 \mathrm{MHz}$ spectrometer in $\mathrm{CDCl}_{3}$. Size-exclusion chromatography (SEC) was performed on a Tosoh EcoSEC HLC-8320GPC instrument equipped with RI and UV detectors and SDV Linear S columns from PSS. Samples were run in toluene at $35{ }^{\circ} \mathrm{C}$ at a rate of $1 \mathrm{~mL} \mathrm{~min}{ }^{-1}$, and molar mass characteristics were calculated using WinGPC Unity 7.4.0 software and linear PDMS standards acquired from PSS. Differential scanning calorimetry (DSC) measurements were performed on a DSCQ1000 from TA Instruments, and thermogravimetric analysis (TGA) was performed on a Q500 from TA Instruments in a nitrogen atmosphere with a heating rate of $10{ }^{\circ} \mathrm{C} \mathrm{min}^{-1}$ from RT to $950{ }^{\circ} \mathrm{C}$. Linear viscoelastic (LVE) data for the films were measured using an ARES-G2 rheometer (TA Instruments) set to a controlled strain mode, with $1 \%$ strain and with frequency sweeps from $100 \mathrm{~Hz}$ to $0.01 \mathrm{~Hz}$ at RT in an ambient atmosphere using a parallel-plate geometry $25 \mathrm{~mm}$ in diameter. Young's moduli were measured using a material tester (Zwick/Roell Zmart.Pro, Zwick GmbH \& Co). The areal dimension of the square sample was $6 \mathrm{~mm} \times 50 \mathrm{~mm}$, and the test specimen was elongated continuously at $10 \mathrm{~mm} \mathrm{~min}^{-1}$ until it reached $15 \%$ strain. The Young's moduli were thereafter calculated from the slopes of the curves at 5\% strain. Stress strain measurements were performed on an in-house-built device, where $2 \mathrm{~cm} \times 2 \mathrm{~cm}$ $\times 73 \mu \mathrm{m}$ to $99 \mu \mathrm{m}$ films were mounted with clamps on a moving stage. The force exerted on the films was then measured as a function of the strain applied by the moving stage. Stress was then calculated from the force assuming the incompressibility of the films. Dielectric relaxation spectroscopy (DRS) was performed on a Novocontrol Alpha-A high performance frequency analyser (Novocontrol Technologies $\mathrm{GmbH} \& \mathrm{Co}$ ) operating in the frequency range $10^{-1}-10^{6} \mathrm{~Hz}$ at room temperature. The diameter of the tested $0.5-1 \mathrm{~mm}$ thick samples were $25 \mathrm{~mm}$. Electrical breakdown tests were performed on an in-house-built device based on international standards (IEC 60243-1 (1998) and IEC 60243-2 (2001)), while film thicknesses were measured through the microscopy of cross-sectional cuts, and the distance between the spherical electrodes was set accordingly with a micrometer stage and gauge. An indent of less than $5 \%$ of sample thickness was added, to ensure that the spheres were in contact with the sample. The polymer film was slid between the two spherical electrodes (radius of $20 \mathrm{~mm}$ ), and the breakdown was measured at the point of contact by applying a stepwise increasing voltage (50-100 V per step) at a rate of 0.5-1 steps per s. Each sample was subjected to 12 breakdown measurements, and an average of these values was given as the breakdown strength of the sample.

The procedures used for synthesising alkyl chloridefunctional copolymers ${ }^{23}$ can be found as ESI. $\dagger$

\section{General procedure for elastomer synthesis}

Co-1, Co-2 or vinyl-terminated PDMS, DMS-V31 or a mixture of these polymers and an 8-functional cross-linker were mixed with treated silica particles (25 wt $\%)$ and inhibitor ( $1 \mathrm{wt} \%, \mathrm{Pt} 88)$ and then treated on a FlackTek Inc. DAC 150.1 FVZ-K SpeedMixer ${ }^{\mathrm{TM}}$. The catalyst (511) (1.5 ppm) was added thereafter and the mixture was speed-mixed once more. The mixture was then poured into a $1 \mathrm{~mm}$ thick steel mould and furthermore coated as $150 \mu \mathrm{m}$ films on a glass substrate and cured at $80^{\circ} \mathrm{C}$ for 2 hours. The different sample compositions quantities can be found as ESI. $\dagger$

\section{Swelling experiments}

Gel fractions were determined using swelling experiments, where samples of all prepared films were swollen in chloroform at RT for 48 hours and placed on a rotary shaking board. The solvent was decanted and the films were washed several times. The samples were thereafter dried for 48 hours to a constant weight in an ambient atmosphere. Gel fractions were calculated as the weight after extraction and drying $\left(m_{\mathrm{e}}\right)$ against the initial weight of the sample $\left(m_{0}\right)$ as $W_{\text {gel }}=m_{\mathrm{e}} / m_{0}$. 


\section{Results and discussion}

Soft silicone elastomers with high dielectric permittivity were prepared using a novel elastomer system based on alkyl chloride-functional copolymers which were prepared according to a previously described procedure. ${ }^{23}$ The copolymers were prepared through the tris(pentafluorophenyl)borane-catalysed Piers-Rubinsztajn reaction of 3-chloropropylmethyldimethoxysilane and hydride-terminated dimethylsiloxane pre-polymers, by using commercially available stating materials. Two different dimethylsiloxane pre-polymer chain lengths constituted the spacer units between the 3-chloropropylmethylsiloxane units. The alkyl chloride-functional siloxane copolymers were end-functionalised with allyldimethylsilane, and the allylgroups allowed for hydrosilylation reactions with hydrideterminated cross-linkers - and thereby the formation of polymer networks. The structure of the alkyl chloride-functional siloxane copolymers, with two different dimethylsiloxane spacer units between the alkyl chloride units, is shown in Fig. 1.

Two types of copolymers with two different spacer lengths between the alkyl chloride-groups were synthesised. One copolymer contained alkyl chloride-groups with $1200 \mathrm{~g} \mathrm{~mol}^{-1}$ dimethylsiloxane spacers between each group (Co-1), and the other copolymer contained alkyl chloride-groups with $580 \mathrm{~g} \mathrm{~mol}^{-1}$ dimethylsiloxane spacers between the functional groups (Co-2). Co-2, with the shorter spacer, thus contained approximately double the amount of alkyl chloride functional groups than Co-1 prepared with the long spacer (at comparable copolymer lengths).

The two synthesised copolymers were characterised by size exclusion chromatography (SEC), and molar mass characteristics were calculated from linear PDMS standards. The molecular weights of Co-1 and Co-2 were both found to be $\bar{M}_{\mathrm{w}} \approx 29000 \mathrm{~g} \mathrm{~mol}^{-1}$, which is a suitable molecular weight for silicone elastomers, since good mechanical properties are obtained when using polymers of 20000 to $30000 \mathrm{~g} \mathrm{~mol}^{-1} .^{24}$ Similar molecular weights were aimed for during the careful synthesis of the two copolymers for easy comparison of their elastomer properties. Furthermore, molecular weights of $29000 \mathrm{~g} \mathrm{~mol}^{-1}$ signify that Co-1 contain approximately 20 alkyl chloride units, whereas Co- 2 contains approximately 40 alkyl chloride units.

The alkyl chloride-functional copolymers were used thereafter to create silicone elastomers with 8 -functional hydride

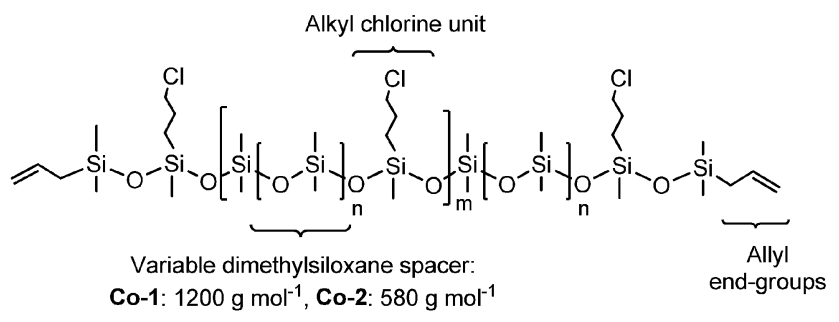

Fig. 1 Structure of alkyl chloride-functional siloxane copolymers with various spacer lengths between the alkyl chloride units and allyl end groups, thereby allowing for hydrosilylation cross-linking reactions. cross-linkers and $25 \mathrm{wt} \%$ surface-treated silica particles as reinforcements, according to Scheme 1. Samples were prepared with pure copolymer or as mixtures with a PDMS of $28000 \mathrm{~g} \mathrm{~mol}^{-1}$ (DMS-V31). An overview of the prepared samples is shown in Table 1.

A pure reference sample made from PDMS (DMS-V31), using similar reaction conditions (same catalyst, cross-linker and particle concentration), was also produced.

To elucidate the amount of bonded (gel fraction) and nonbonded (sol fraction) species in the networks, the gel fractions of the elastomers were determined from swelling experiments with chloroform. From Table 2 it can be seen that the gel fractions for the films with the pure copolymers, Co-1 and Co-2, and the mixtures of copolymers/DMS-V31 all had high gel fractions, which in all cases were around or above $90 \%$ and were apparently independent of the concentration of alkyl chloride units. The gel fractions are all within an acceptable limit for silicone networks and are comparable with previously obtained results for soft PDMS elastomers. ${ }^{19,25}$

The effect of the degree of alkyl chloride-functional copolymers on the thermal transition behaviour of the elastomer films was determined by DSC. The reference film showed clear melting and crystallisation temperatures at $T_{\mathrm{m}}=-46{ }^{\circ} \mathrm{C}$ and $T_{\mathrm{c}}=-75{ }^{\circ} \mathrm{C}$, respectively. For films prepared with the alkyl chloride-functional copolymers, Co-1 and Co-2, no $T_{\mathrm{m}}$ or $T_{\mathrm{c}}$ was observed, which means that no crystalline regions were present in the films, most probably due to the alkyl chloride side-chains, which prevent the alignment of linear polymer segments necessary for crystallisation. Only for the Co-2_25 film, with 75 mol\% DMS-V31, was $T_{\mathrm{c}}$ observed, whereas the other mixtures had only a clear $T_{\mathrm{m}}$.

The effect of the alkyl chloride-functional copolymers on the thermal stability of the elastomer films was determined by TGA, and the resulting thermograms can be found as ESI. $\dagger$ The first thermal degradation temperatures for the samples prepared with alkyl chloride-functional copolymers decreased slightly compared to the reference film. The second degradation step temperatures, however, remained similar to those for the reference film; therefore, overall, thermal degradation did not alter significantly for the films with the alkyl chloride-functional copolymers compared to the reference film. Mineralisation of the Co-2 film, however, occurred to a greater extent; nevertheless the degradation temperatures for this film still remained similar to those of the other films.

The viscoelastic properties of the elastomer films prepared with alkyl chloride-functional copolymers, as well as the reference film, were investigated by determining their shear storage and shear loss moduli. The results for the films with the different compositions of alkyl chloride-functional copolymers are shown in Fig. 2. Furthermore, the resulting shear storage moduli $\left(G^{\prime}\right)$ and losses $(\tan \delta)$ at $1 \mathrm{~Hz}$ are summarised in Table 2. It is evident from Fig. 2 and Table 2 that all films prepared with alkyl chloride-functional copolymers have lower moduli than the reference film based on pure PDMS. Furthermore, viscous loss, $\tan \delta$, has only increased slightly for one sample, namely Co-2_50, while viscous losses for all other films with alkyl chloride functional copolymers are maintained at the 

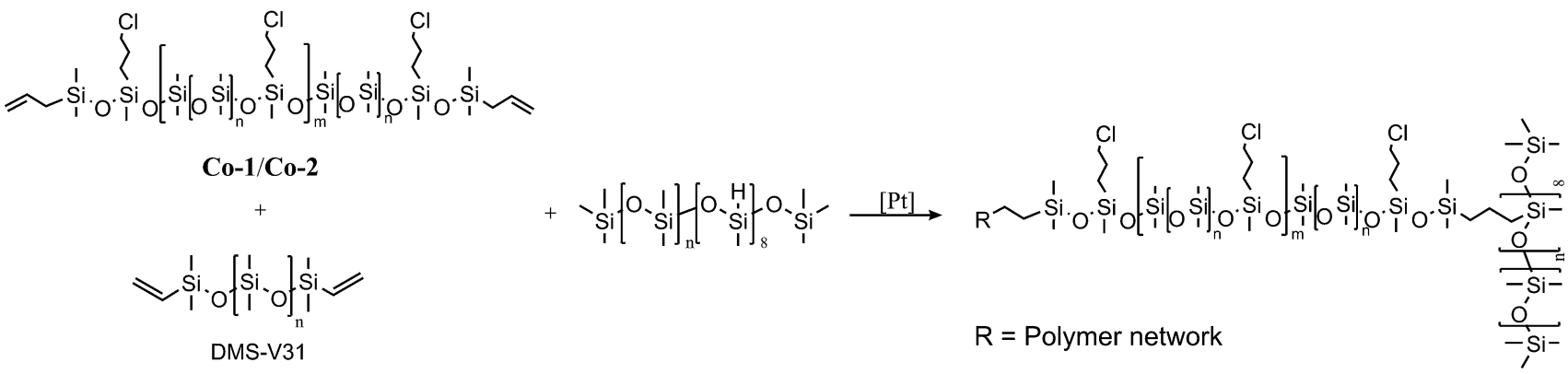

Scheme 1 Cross-linking reaction between Co-1 or Co-2, DMS-V31 and a hydride-functional cross-linker.

Table 1 Overview of the prepared elastomer samples

\begin{tabular}{lcc}
\hline Entry & $\begin{array}{c}\text { Content of copolymer } \\
{[\mathrm{mol} \%]}\end{array}$ & $\begin{array}{l}\text { Content of DMS-V31 } \\
{[\mathrm{mol} \%]}\end{array}$ \\
\hline DMS-V31 & 0 & 100 \\
Co-1_50 & 50 & 50 \\
Co-1 & 100 & 0 \\
Co-2_25 & 25 & 75 \\
Co-2_50 & 50 & 50 \\
Co-2 & 100 & 0
\end{tabular}

same level as the reference film and are all low. This proves that the mechanical integrity of the films with alkyl chloride functional copolymers has not been lost, even though the films are significantly softer than the reference film.

The stress-strain behaviour and Young's moduli of the films prepared with alkyl chloride-functional copolymers were determined through tensile tests. The resulting stress-strain curves are shown in Fig. 3, and the Young's moduli, which are calculated as the slopes of the stress-strain curves at low strains, are summarised in Table 2 . The stress-strain curves in Fig. 3 illustrate the softening effect of the alkyl chloridefunctional copolymers on the films. Co-1 shows a significantly reduced elastic modulus and increased strain at breakage. Co-2 also shows increased strain at breakage compared to those films containing copolymers mixed with the reference polymer DMSV31 and the pure reference film. Furthermore, all samples prepared with Co-2, which contains the highest concentration

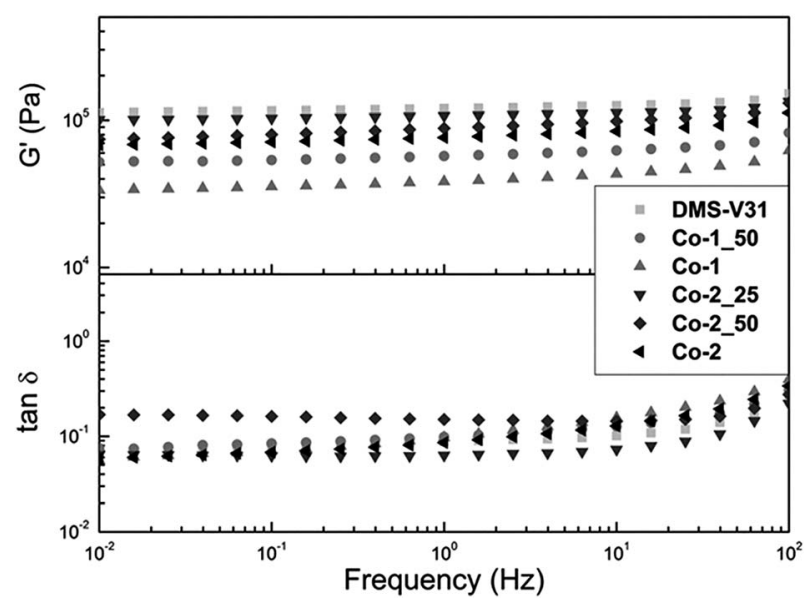

Fig. 2 Storage moduli $\left(G^{\prime}\right)$ and loss ( $\tan \delta$ ) as functions of frequency for films prepared with alkyl chloride-functional copolymers.

of alkyl chloride units, are stiffer than those prepared with Co-1, which has a longer dimethylsiloxane spacer between the alkyl chloride units and thus a lower concentration of functional units. The shapes of the stress-strain curves for all films containing alkyl chloride-functional copolymers are highly favourable for electromechanical actuation, since alkyl chloridefunctional copolymers lead to elastomers which do not favour from pre-stretch to the same extent as traditional non-linear elastomers, which tend to strain-soften at higher strains. ${ }^{2,26}$ Elastomers prepared with alkyl chloride-functional copolymers

Table 2 Gel fraction $\left(W_{\text {gel }}\right)$, dielectric permittivity $\left(\varepsilon^{\prime}\right)$ and loss tangent (tan $\left.\delta\right)$ at $100 \mathrm{~Hz}$, breakdown strengths $\left(E_{\mathrm{B}}\right)$, storage $\left(G^{\prime}\right)$ moduli and loss $(\tan \delta)$, Young's moduli as well as the figure of merit for films with alkyl chloride-functional copolymers and the PDMS reference, DMS-V31

\begin{tabular}{|c|c|c|c|c|c|c|c|c|}
\hline \multirow[b]{2}{*}{$\begin{array}{l}\text { Film with } \\
\text { entry }\end{array}$} & \multirow{2}{*}{$\begin{array}{l}\text { Gel fraction } \\
W_{\text {gel }}[\%]\end{array}$} & \multicolumn{2}{|c|}{ Dielectric spectroscopy } & \multirow{2}{*}{$\begin{array}{l}\text { Electrical breakdown } \\
E_{\mathrm{B}} \\
{\left[\mathrm{V} \mu \mathrm{m}^{-1}\right]}\end{array}$} & \multicolumn{2}{|l|}{ Rheology } & \multirow{2}{*}{$\begin{array}{l}\text { Tensile tests } \\
\mathrm{Y} \text { @ } 5 \% \\
\text { strain }[\mathrm{MPa}]\end{array}$} & \multirow{2}{*}{$\begin{array}{l}\begin{array}{l}\text { Figure of } \\
\text { merit }\end{array} \\
F_{\text {om }} / F_{\text {om_ref }}\end{array}$} \\
\hline & & $\begin{array}{l}\varepsilon^{\prime} \\
\text { @ } 100 \mathrm{~Hz}\end{array}$ & $\begin{array}{l}\tan \delta \\
\text { @100 Hz }\end{array}$ & & $\begin{array}{l}G^{\prime} \\
\text { (a) } 1 \mathrm{~Hz}[\mathrm{kPa}]\end{array}$ & $\begin{array}{l}\tan \delta \\
\text { @1 Hz }\end{array}$ & & \\
\hline DMS-V31 & 98 & 3.3 & $6.2 \times 10^{-4}$ & 81.6 & 119.7 & 0.088 & 3.8 & 1.0 \\
\hline Co-1_50 & 90 & 4.1 & $5.3 \times 10^{-4}$ & 84.3 & 57.2 & 0.098 & 0.95 & 5.3 \\
\hline Co-1 & 85 & 4.4 & $5.9 \times 10^{-4}$ & 73.9 & 38.4 & 0.097 & 0.40 & 10.4 \\
\hline Co-2_25 & 96 & 3.9 & $4.3 \times 10^{-4}$ & 101.2 & 107.1 & 0.063 & 2.8 & 2.5 \\
\hline Co-2_50 & 94 & 4.4 & $4.3 \times 10^{-4}$ & 99.8 & 88.3 & 0.15 & 1.5 & 5.1 \\
\hline Co-2 & 92 & 4.7 & $9.5 \times 10^{-4}$ & 94.4 & 76.4 & 0.085 & 1.0 & 7.2 \\
\hline
\end{tabular}




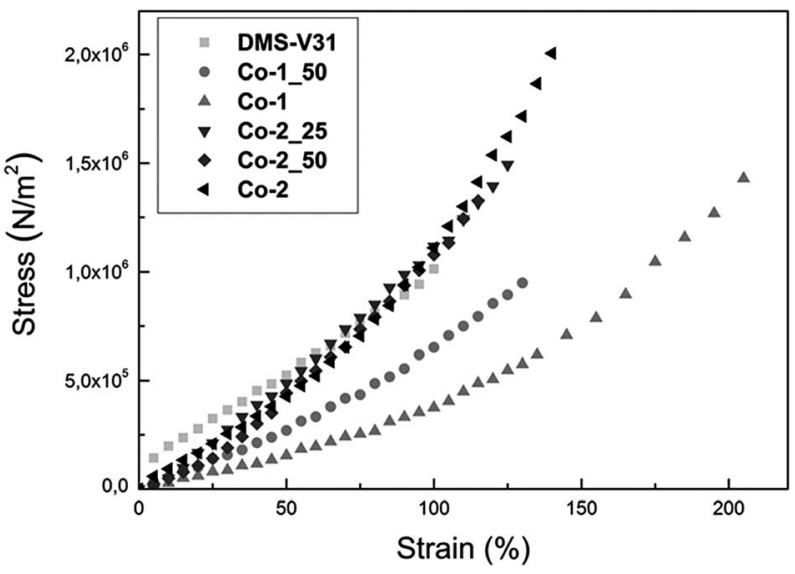

Fig. 3 Stress-strain curves for films prepared with alkyl chloridefunctional copolymers.

are soft from zero strain and harden gradually when further strain is applied. This strain-hardening nature of elastomers prepared with alkyl chloride-functional copolymers suppresses electromechanical instability (EMI), which can be understood as follows: as the voltage over the DE is increased, the elastomers thin down and an even higher electrical field is obtained at the given voltage. If the elastomer is strain-softening, this positive feedback may cause direct electrical breakdown. ${ }^{27-30}$

The dielectric properties of the samples were determined through dielectric spectroscopy, the results for which are shown in Fig. 4. For all films prepared with alkyl chloride-functional copolymers dielectric permittivity is seen to increase compared to the reference film, for which $\varepsilon^{\prime}=3.3$. Furthermore, permittivity increases in line with increasing alkyl chloride-group content in films, reaching as high as $\varepsilon^{\prime}=4.7$ for the film prepared with Co-2. This corresponds to an increased permittivity of $43 \%$. For all films, dielectric permittivity is seen to stay constant throughout the entire frequency range, indicating that no Maxwell polarisation ${ }^{31}$ processes are taking place. This can also be seen from the losses, $\tan \delta$, which remain as low as the PDMS reference sample for all prepared materials.

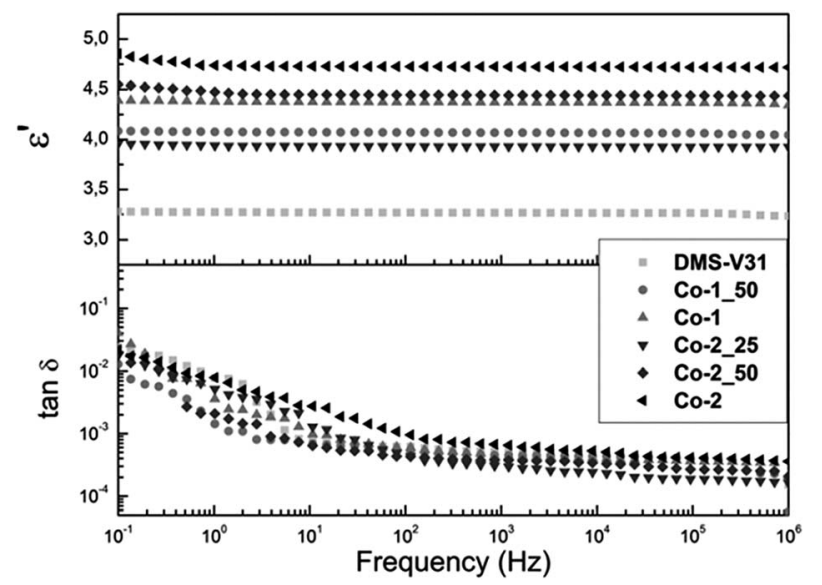

Fig. 4 Dielectric permittivity $\left(\varepsilon^{\prime}\right)$ and loss tangent ( $\left.\tan \delta\right)$ as functions of frequency for films prepared with alkyl chloride-functional copolymers.
The conductivity of the samples prepared with alkyl chloridefunctional copolymers is shown in Fig. 5. It is evident from Fig. 5 that films with high Co-2 content show slightly increased electric conductivity at low frequencies, as conductivity becomes independent of frequency. The observed conductivities, however, remain at a very low level. All other samples show no increased conductivity compared to the reference film based on pure PDMS.

The electrical breakdown strengths, $E_{\mathrm{B}}$, for films with alkyl chloride-functional copolymers, as well as the reference film, are presented in Table 2. For all films, electrical breakdown field strength is increased or maintained at the same level compared to the reference film. The high breakdown strengths for films containing Co-1 or Co-2 are not the result of increased elastic moduli, which is often the case. ${ }^{32}$ This suggests that the use of the new alkyl chloride-functional copolymer as matrices for DEs does not compromise the dielectric breakdown strength of the films and in most cases the presence of the copolymers actually improves breakdown strength. This could be due to a low degree of chemical and physical impurities (since the copolymers are all purified after synthesis), which has a large influence on the dielectric strength of insulating materials. ${ }^{33,34}$

Sommer-Larsen and Larsen ${ }^{35}$ defined a universal expression which, through a single parameter, the figure of merit, $F_{\text {om }}$, can be used to evaluate the performance of a $\mathrm{DE}$ at a constant potential. The figure of merit depends on the dielectric constant, dielectric breakdown strength and the Young's modulus of the elastomer material, and it is defined as:

$$
F_{\text {om }}=\frac{3 \varepsilon^{\prime} E_{\mathrm{B}}^{2}}{Y}
$$

The properties of the films prepared with the alkyl chloridefunctional copolymers can be compared to the properties of the PDMS reference material by calculating the $F_{\text {om }}$ of a given sample relative to the $F_{\text {om }}$ of the reference material $\left(F_{\text {om }} / F_{\text {om_ref }}\right)$. The results of these calculations are shown in Table 2, from which it is evident that the figure of merit relative to the reference film improves for all films prepared with alkyl chloride-

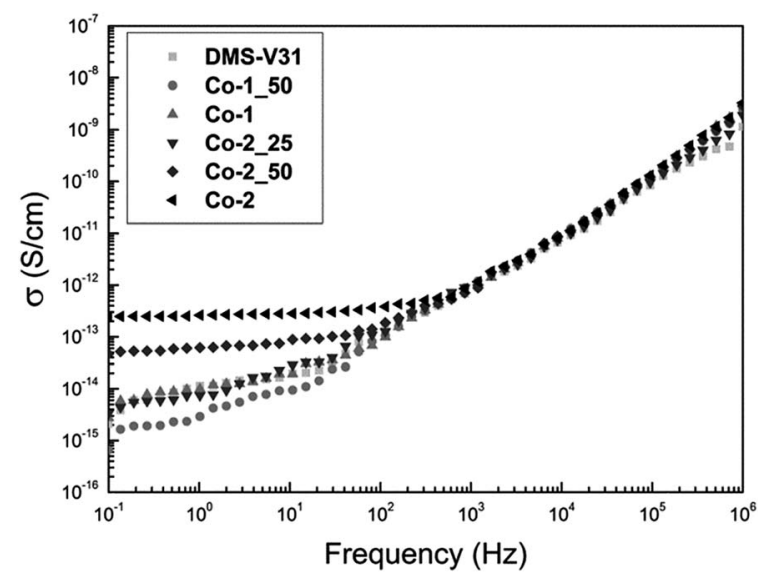

Fig. 5 Conductivity as function of frequency for films prepared with alkyl chloride-functional copolymers. 
functional copolymers. The largest increase in the figure of merit is obtained for films with pure alkyl chloride-functional copolymers, where the figure of merit is increased 10 and 7 times, respectively, compared to the reference film. For the film prepared with Co-1, the high figure of merit is obtained because of the high dielectric permittivity and a low Young's modulus. For the film with pure Co-2, the high figure of merit is obtained due to high dielectric permittivity and high dielectric breakdown strength as well as the low Young's modulus.

The prepared alkyl chloride-functional copolymers have great potential in the preparation of soft silicone elastomer systems with high electromechanical responses. We are currently investigating the use of alkyl chloride-functional copolymers in formulated elastomer systems, thus elucidating their electromechanical properties.

\section{Conclusions}

A new soft dielectric elastomer matrix with high dielectric permittivity was prepared through the use of alkyl chloridefunctional siloxane copolymers. Elastomer films prepared with alkyl chloride-functional copolymers showed a high level of mechanical integrity based on their high gel fractions and low viscous losses. Thus, decreases in Young's moduli, caused by the new copolymers, did not decrease mechanical stability and thereby the lifetime of the dielectric elastomers. Furthermore, all elastomers prepared with alkyl chloride-functional copolymers were shown to be strain-hardening, which is a favourable property for dielectric elastomers due to the suppression of electromechanical instability. High dielectric permittivities were obtained for films with alkyl chloride-functional copolymers (e.g. a 43\% increase), while dielectric losses remained at a very low level. Electrical breakdown also remained high compared to a pure PDMS reference material. The synergistic effect of the low elastic moduli, high dielectric permittivity and high dielectric breakdown strengths thus resulted in a predicted ten-fold improved performance.

\section{Acknowledgements}

The authors wish to acknowledge Innovations Fonden for its financial support.

\section{Notes and references}

1 C. Löwe, X. Zhang and G. Kovacs, Adv. Eng. Mater., 2005, 7, 361-367.

2 P. Brochu and Q. Pei, Macromol. Rapid Commun., 2010, 31, 10-36.

3 R. Heydt, R. Kornbluh, J. Eckerle and R. Pelrine, Proc. SPIE, 2006, 6168, 61681M.

4 Z. Yu, W. Yuan, P. Brochu, B. Chen, Z. Liu and Q. Pei, Appl. Phys. Lett., 2009, 95, 192904.

5 R. Sarban, R. W. Jones, E. Rustighi and B. R. Mace, J. Syst. Des. Dyn., 2011, 5, 643-652.

6 K. Ahnert, M. Abel, M. Kollosche, P. J. Jørgensen and G. Kofod, J. Mater. Chem., 2011, 21, 14492-14497.
7 F. B. Madsen, I. Dimitrov, A. E. Daugaard, S. Hvilsted and A. L. Skov, Polym. Chem., 2013, 4, 1700-1707.

8 F. B. Madsen, A. E. Daugaard, S. Hvilsted, M. Y. Benslimane and A. L. Skov, Smart Mater. Struct., 2013, 22, 104002.

9 F. Carpi and D. De Rossi, IEEE Trans. Dielectr. Electr. Insul., 2005, 12, 835-843.

10 G. Ouyang, K. Wang and X. Y. Chen, J. Micromech. Microeng., 2012, 22, 074002.

11 H. Liu, L. Zhang, D. Yang, Y. Yu, L. Yao and M. Tian, Soft Mater., 2013, 11, 363-370.

12 H. Stoyanov, P. Brochu, X. Niu, E. Della Gaspera and Q. Pei, Appl. Phys. Lett., 2012, 100, 262902.

13 S. Vudayagiri, S. Zakaria, L. Yu, S. S. Hassouneh, M. Benslimane and A. L. Skov, Smart Mater. Struct., 2014, 23, 105017.

14 P. Lotz, M. Matysek, P. Lechner, M. Hamann and H. F. Schlaak, Proc. SPIE, 2008, 6927, 692723.

15 Y. Liu, L. Liu, Z. Zhang and J. Leng, Smart Mater. Struct., 2009, 18, 095024.

16 G. Gallone, F. Galantini and F. Carpi, Polym. Int., 2010, 59, 400-406.

17 A. L. Larsen, P. Sommer-Larsen and O. Hassager, Proc. SPIE, 2004, 5385, 108-117.

18 A. G. Bejenariu, L. Yu and A. L. Skov, Soft Matter, 2012, 8, 3917-3923.

19 F. B. Madsen, A. E. Daugaard, C. Fleury, S. Hvilsted and A. L. Skov, RSC Adv., 2014, 6939-6945.

20 F. Carpi, G. Gallone, F. Galantini and D. De Rossi, Adv. Funct. Mater., 2008, 18, 235-241.

21 H. Liu, L. Zhang, D. Yang, N. Ning, Y. Yu, L. Yao, B. Yan and M. Tian, J. Phys. D: Appl. Phys., 2012, 45, 485303.

22 S. Risse, B. Kussmaul, H. Krüger and G. Kofod, Adv. Funct. Mater., 2012, 22, 3958-3962.

23 F. B. Madsen, I. Javakhishvili, R. E. Jensen, A. E. Daugaard, S. Hvilsted and A. L. Skov, Polym. Chem., 2014, 5, 7054-7061.

24 A. L. Larsen, P. Sommer-Larsen and O. Hassager, e-Polymers, 2004, 050, 1-18.

25 S. M. G. Frankær, M. K. Jensen, A. G. Bejenariu and A. L. Skov, Rheol. Acta, 2012, 51, 559-567.

26 G. Kofod, J. Phys. D: Appl. Phys., 2008, 41, 215405.

27 R. E. Pelrine, R. D. Kornbluh and J. P. Joseph, Sens. Actuators, 1998, 64, 77-85.

28 J. Zhu, H. Stoyanov, G. Kofod and Z. Suo, J. Appl. Phys., 2010, 108, 074113.

29 X. Zhao, W. Hong and Z. Suo, Phys. Rev. B: Condens. Matter Mater. Phys., 2007, 76, 134113.

30 X. Zhao and Z. Suo, Appl. Phys. Lett., 2007, 91, 061921.

31 K. Goswami, F. Galantini, P. Mazurek, A. E. Daugaard, G. Gallone and A. L. Skov, Smart Mater. Struct., 2013, 22, 115011.

32 M. Kollosche and G. Kofod, Appl. Phys. Lett., 2010, 96, 071904.

33 J.-O. Bostrom, E. Marsden, R. N. Hampton, U. Nilsson and H. Lennartsson, IEEE Electr. Insul. Mag., 2003, 19, 6-12.

34 F. B. Madsen, L. Yu, A. E. Daugaard, S. Hvilsted and A. L. Skov, Polymer, 2014, 55, 6212-6219.

35 P. Sommer-Larsen and A. L. Larsen, Proc. SPIE, 2004, 5385, 68-77. 